\title{
Sociossemiótica: uma teoria geral do sentido ${ }^{1}$
}

Eric Landowski

Resumo: Fora do texto, a semiótica continua! De fato, além e aquém da análise da significação investida nos textos e nos discursos, a semiótica (especialmente a de origem greimasiana) pretende hoje dar conta de como o sentido emerge também das práticas mais diversas, de nossas relações vividas com os objetos que nos circundam ou dos quais fazemos uso, numa palavra, da vida cotidiana nas suas múltiplas dimensões, inclusive a do sensível. Para isso, a disciplina teve que se desenvolver como uma teoria geral da geração do sentido na interação. O artigo seguinte apresenta sucintamente os princípios dessa abordagem renovada sob o nome de "sociossemiótica ».

Palavras-chave: sociossemiótica; regimes de sentido e interação; junção; união.

Abstract: Sociosemiotics: a general theory of meaning - Today, besides the analysis of meaning invested in texts and discourses, semiotics (and especially its version originating in Greimas' works) claims to account for the way how sense emerges from daily life and lived experience with its many dimensions, from our sensitive relations with the world around and with the objects we use, in a word, from all kinds of human practices. During the last two decades, in order to reach this scope,the discipline developped as a general theory of sense production through interaction. The following article presents the basic principles of this renewed « sociosemiotic » approach.

Keywords: sociosemiotics; regimes of meaning and interaction; junction; union.

No escopo da semiótica de inspiração saussuro-hjelmsleviana, a etiqueta «sociossemiótica»se emprega para designar, segundo os contextos, seja um dos ramos especializados da disciplina — aquele que toma especificamente por objeto o social —, seja uma das principais correntes teóricas que se oferecem atualmente para renovar a análise dos fatos de significação em geral, qualquer que seja o tipo de domínio empírico considerado.

1 Esse texto foi adaptado por E. Landowski em dezembro de 2013 a partir de uma versão anterior publicada em francês em D. Ablali et al., Vocabulaire des études sémiotiques et sémiologiques, Paris-Besançon, Honoré Champion-Presses universitaires de Franche-Comté, 2009. 


\section{Um terreno específico, uma teoria geral}

Entendida segundo a primeira acepção, a sociossemiótica desenvolve-se, desde a metade dos anos 1970, sobretudo na França, na Itália e na América Latina, sob a forma de um número continuadamente crescente de pesquisas sobre domínios tão variados que sua enumeração pode parecer heteróclita. À análise crítica das mídias seguiu-se a dos discursos e das práticas da política e do direito, depois a das situações e dos espaços no interior dos quais os atores sociais comunicam-se, construindo e trocando entre eles formas carregadas de sentido e de valor, até chegar ao estudo das modalidades da interface entre os objetos e seus utilizadores. Deste modo, passo a passo, delineou-se uma problemática abrangente, englobando o conjunto das práticas da cotidianidade (GREIMAS 1976; FLOCH 1995; LANDOWSKI 1997; MARRONE 2001; MARSCIANI 2007).

Segundo a outra perspectiva, entretanto, a sociossemiótica não pode mais ser definida pelo caráter «social» dos objetos que ela estuda. De fato, seu objeto é o sentido enquanto tal, e o papel que ela assume é construir a teoria geral desse objeto. Deixando de constituir uma " aplicação » da disciplina a um campo particular, ela se apresenta — do mesmo modo que a sua concorrente (e cúmplice), a «semiótica tensiva» — como uma das formas atuais da semiótica geral. O que faz a sua especificidade é uma opção teórica da qual ela não tem o monopólio, mas da qual ela procura extrair todas as consequências, a saber a ideia de uma relação necessária, constitutiva, ligando sentido e interação (LANDOWSKI 2004, 2005: 30-31).

Todavia, essas duas acepções, uma mais especializada, outra mais geral, longe de se excluírem, conjugam-se. E é precisamente a noção de interação que lhes serve de articulação. Ao mesmo tempo que essa noção permite fundar uma teoria sociossemiótica sobre o plano mais geral, ela também garante, sobre o plano analítico, a unidade do campo sociossemiótico, ou, ao menos, a possibilidade de projetar sobre ele um olhar constante e coerente a despeito da diversidade dos objetos empíricos tomados em consideração. Em uma palavra, pensar sociossemioticamente a questão geral do sentido, ou analisar sociossemioticamente objetos de ordens diversas, é, em todos os casos, colocar a noção de interação no coração da problemática da significação.

\section{Aquém dos signos e além dos códigos}

Um sobrevoo histórico fará compreender como esta concepção foi pouco a pouco se desenhando. Em um primeiro momento, em torno do final dos anos 1960, a ideia de sociossemiótica era ligada, no espírito de seu promotor na época, A. J. Greimas, àquela de «sistema das conotações sociais». Considerando que as práticas semióticas, verbais, gestuais ou outras constituem manifestações por meio das quais se exprimem «conotativamente» as posições sociais dos agentes, propunha-se inventariar as correspondências entre 
tipos de comportamentos (em primeiro lugar linguísticos) e tipos de papéis sociais (definidos a partir de variáveis tais como a idade, o sexo, o estatuto profissional, etc.). Próxima da sociolingúistica norte-americana então em voga, essa problemática apresentava um inconveniente maior: aquele de reduzir o sentido a uma função de expressão segunda, subordinada à primazia das estruturas sociais e, desse modo, de excluir toda autonomia do semiótico. Compreende-se que nessas condições, apesar de uma certa insistência da parte de seu promotor, ela não tenha feito adeptos e tenha sido praticamente rejeitada. De fato, o que se designa hoje pelo nome de sociossemiótica só começou a tomar corpo a partir do dia em que um certo número de investigadores tiveram a iniciativa de propor uma pesquisa direcionada exatamente na contramão dessa ótica. Podem-se resumir os seus princípios em três pontos (LANDOWSKI 1989; 2004: 18-37).

O projeto sociossemiótico sob sua forma atualmente efetiva assume como hipótese primeira que as produções de sentido não devem ser tomadas como «representações» do social considerado enquanto referencial ou realidade primeira. São, ao contrário, as práticas de construção, negociação, intercâmbio de sentido que vêm construindo o «social» enquanto universo de sentido. Do mesmo modo vêm sendo delimitados os campos do «político», do «jurídico», do «literário» etc. Paralelamente, esse projeto nasce da decisão de deixar de uma vez por todas aos semiologistas as noções de código e de signo. Por oposição, a (socio) semiótica pretende construir uma problemática mais abrangente da significação concebida ao mesmo tempo como uma totalidade dependente da articulação estrutural imanente a cada discurso ou prática (e não de uma simples justaposição de elementos combinatórios) e como o resultado de uma construção negociada entre os actantes (e não como o produto de um simples reconhecimento de unidades pré-codificadas). Correlativamente, o projeto sociossemiótico procede de uma última escolha decisiva: a de privilegiar não a descrição de sistemas que determinariam a produção e a recepção das manifestações significantes (o que acabaria por encerrar as práticas de sentido numa função de perpétua reprodução do mesmo), mas a análise dos processos, ou seja, justamente, das interações (entre sujeitos ou entre o mundo e os sujeitos) que presidem a construção mesma do sentido e tornam em consequência possível a emergência de configurações inéditas. Menos que uma análise do sentido realizado, investido nos objetos - nos enunciados, nos textos, nas coisas que nos circundam ou nos comportamentos que nós observamos - , a sociossemiótica se propõe como uma teoria da produção e da apreensão do sentido em ato.

\section{Da junção à união}

Concentrando assim a atenção sobre o ato e mais especificamente sobre a dimensão interacional dos processos, a sociossemiótica inscreve-se no prolongamento da semiótica standard, frequentemente considerada ela mesma como uma semiótica da ação («em papel»). Mas se uma retoma da outra suas principais aquisições, a saber 
a problemática actancial e modal conhecida enquanto gramática narrativa, é somente com certas reservas. Pois a forma que a teoria sociossemiótica acaba por tomar resulta de uma crítica metódica do modelo standard (LANDOWSKI 2004: 39-49). Ao procurar superar as pressuposições filosóficas e antropológicas desse modelo e completar suas lacunas, a sociossemiótica foi levada a adicionar à conceituação semio-narrativa clássica um certo número de complementos que tomam finalmente lugar num modelo novo, ao mesmo tempo integrador e inovador (LANDOWSKI 2005: 71-92).

$\mathrm{Na}$ base quase filosófica da gramática narrativa clássica, encontra-se o postulado segundo o qual todas as flutuações que afetam a condição material e moral dos sujeitos dependem de operações de junção que alternativamente os põem ou de posse dos objetos que valorizam (conjunção), ou em estado de privação (disjunção) (GREIMAS \& COURTÉS 1979). Ora, tal modelização permite dar conta somente de um aspecto, muito parcial, de nossas relações com o mundo - de seu aspecto «econômico». E além dessa dimensão da vida, existe, enquanto positividades também semioticamente analisáveis, interações independentes de qualquer transferência de objetos entre sujeitos. De fato, antes de se decompor em unidades discretas oferecidas a nossa curiosidade, nossa cobiça ou nossa apreensão, o mundo nos é presente enquanto totalidade fazendo sentido. É assim que, numa perspectiva em parte inspirada nos trabalhos de Sartre e de Merleau-Ponty, foi-se levado a postular, paralelamente à lógica da junção, a pertinência semiótica de uma outra lógica do sentido, fundada sobre a co-presença sensível dos actantes - o que foi convencionado chamar de lógica da união (LANDOWSKI 2004: 62-66, 136-137).

Segundo a lógica da junção, a compreensão do mundo passa pelo deciframento de formas que, verbais ou não, são consideradas como equivalentes a outros tantos textos que, supostamente, «quereriam» dizer-nos qualquer coisa. Ao contrário, segundo a lógica da união, nós não olhamos mais, ou não ainda, o mundo como uma rede de significantes a decifrar. Entretanto, apesar disso, já existem sentido e valor. É que, não havendo como localizar na superfície das coisas as marcas de discursos inteligíveis que nos seriam direcionados, nós nos deixamos então impregnar pelas qualidades sensíveis inerentes às coisas mesmas. É, portanto, necessário distinguir dois tipos de processos de significância: a leitura, decifração das "significações", fundada sobre o reconhecimento de formas figurativas, e a captura, apreensão do "sentido" que emana das qualidades sensíveis — plásticas, rítmicas, estésicas — imanentes aos objetos.

Sublinhamos que nem um nem o outro desses regimes se define por referência a uma classe determinada de elementos à qual ele se aplicaria especificamente, mas que aquilo que os separa deve-se à diferenca dos tipos de olhar que eles implicam respectivamente, sobre o mundo, qualquer que seja o elemento visado. Mais ainda, leitura ou captura, cada uma implica na realidade, da parte do sujeito, uma modalidade diferente de "ser no mundo" e, por esta razão mesmo, entra em correlação com os modelos praxiológicos oriundos da gramática narrativa enquanto problemática da interação. 
Assim deve-se esperar que aos distintos modos de significância, uns da ordem da leitura, outros da captura, correspondam, em termos de narratividade, regimes de interação também distintos (LANDOWSKI 2007).

Para mostrar isso, vamos recorrer a dois exemplos literários. Primeiro, o herói de O vermelho e o Negro, de Stendhal, Julien Sorel. Da parte dele, a decifração das significações é efetuada por meio de uma meticulosa leitura do mundo (e, mais tecnicamente, da leitura de suas "figuras de superfície"), que é acompanhada pelo comportamento social característico de alguém que se valia de intrigas: Julien é um sujeito programado para manipular. No extremo oposto, Goliadkine, personagem central do conto de Dostoïevski, O Duplo, apresenta-se como absolutamente incapaz de retirar alguma significação clara das intrigas que, ele crê, são tramadas ao seu redor: é uma linguagem que ele não sabe «ler». Inversamente, a cada instante, prolifera a seus olhos, sobre o modo da captura isto é, no contato com as qualidades plásticas do mundo que o circunda (ou estésicas dos corpos que ele margeia) — , uma multiplicidade de tropismos que, na medida em que, em si mesmos, fazem sentido para ele, comandam inteiramente sua maneira de agir em sociedade e o que se pode chamar sua praxis existencial: longe de programar o que quer que seja, ele procura entrar em sintonia com o outro, no instante; longe de manipular quem quer que seja, ele se entrega ao puro acaso do que advirá, colocando assim em ação (sem sucesso) dois regimes de sentido e de interação diametralmente opostos àqueles que privilegiava (aliás em seu próprio detrimento) o herói de Stendhal: o regime do ajustamento ao outro e aquele do assentimento aos decretos da sorte.

\section{Regimes de sentido e regimes de interação}

Entre esses diversos regimes, a semiótica narrativa standard reconhecia somente dois: a «operação», ou ação programada sobre as coisas, e sobretudo a «manipulação», entre sujeitos. O que os distingue sociossemioticamente são os princípios sobre os quais eles se fundam respectivamente: de um lado um princípio geral de regularidade que, congelando os papéis dos protagonistas da ação, garante (em princípio) a eficácia de nossas intervenções sobre o mundo; de outro, um princípio de intencionalidade cujo funcionamento supõe o reconhecimento recíproco dos parceiros da ação enquanto sujeitos dotados de "competências modais" (do tipo querer, saber, etc.) (LANDOWSKI 2005:17-20, 34-39). Foi assim que a gramática narrativa colocou em relevo a figura do «manipulador» e, em menor grau, a do «programador». Ao contrário, nem o sujeito confiante na sua capacidade de sentir ao vivo as potencialidades de uma situação, de tirar vantagem da propensão das coisas ou das pessoas, de apreender e de explorar de improviso o kairos o batizamos de "oportunista" —, nem o "fatalista" decidido a entregar-se à sorte, encontravam lugar nesse quadro. Tanto a observação da interação, quanto a própria experiência que temos, nos obrigam a reconhecer-Ihes um lugar no modelo. Daí a necessidade de introduzir ao lado dos regimes precedentes - que, ao perder seu monopólio, não perdem nada 
de sua pertinência — dois regimes complementares, respectivamente fundados sobre um princípio de sensibilidade e um princípio de aleatoriedade: aqueles do ajustamento e do assentimento (LANDOWSKI 2005: 43-47, 64-71).

Uma vez superados os limites do modelo juntivo, vê-se assim que novas possibilidades se abrem para dar conta da diversidade de modos de apreensão do sentido na interação e tentar construir uma teoria geral. Pode-se resumi-la sob a forma esquemática seguinte (LANDOWSKI 2005: 72):

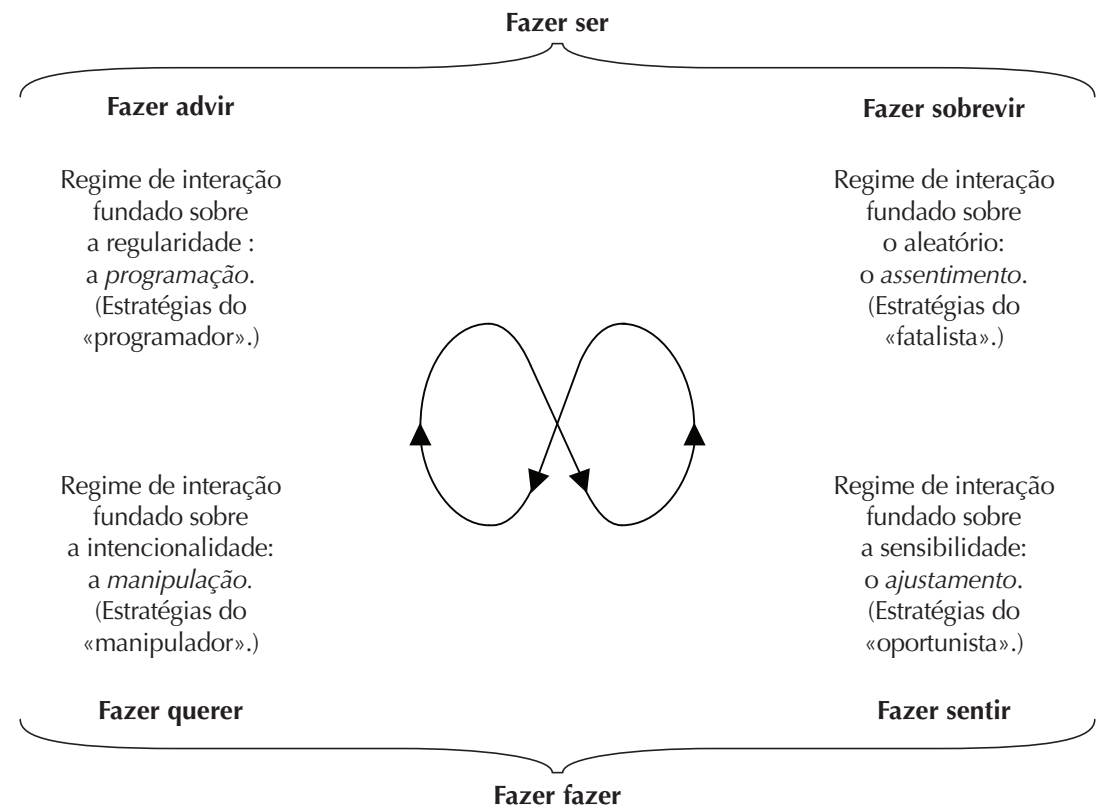

Formando sistema e tendo por conseguinte a vocação de se articular e de se combinar entre si, as quatro fórmulas às quais se chega permitem dar conta da variedade e do caráter geralmente compósito, híbrido ou polivalente das práticas interacionais observáveis sobre os terrenos os mais diversos, inclusive aquele da construção do objeto de conhecimento nas nossas disciplinas com vocação "científica". Fortemente integrador, uma vez que ele visa a dar conta não somente das regularidades mas também dos acidentes da construção do sentido, esse modelo implica uma moral da interação, ou uma ética do sentido. Nessa medida, ele convida a uma reflexão nova sobre o papel, o estatuto e a vocação de nossa disciplina, a meio caminho entre descrições antropológicas e reflexão filosófica.

Seguem algumas definições de base relativas principalmente aos dois regimes introduzidos mais recentemente no quadro da gramática da interação.

\section{O regime do assentimento (ou álea)}

\section{Acidente}

Ver Álea, Assentimento, Papel 


\begin{abstract}
Álea
Do mesmo modo que a regularidade constitui o princípio pressuposto por toda programação, que a intencionalidade é a base necessária para toda manipulação estratégica e que a sensibilidade é a condição de toda interação em forma de ajustamento, o álea (ou melhor, a aleatoriedade) constitui, do ponto de vista de uma sociossemiótica da interação, o princípio fundador de um regime de sentido e de interação específico, o regime do acidente ou, mais precisamente, do assentimento ao imprevisível. Capaz, sob a figura do «azar», de fazer fracassar ou vencer qualquer programa em curso, qualquer manipulação, qualquer ajustamento, o álea faz função de actante «joker» e apresenta o estatuto de um auto-destinador paradoxal. Por definição, ele não depende de nenhuma instância que Ihe seja exterior. Mas tampouco pode-se dizer que ele dependa de si mesmo como seria o caso de um ator que instauraria seu próprio dever-fazer. Ao contrário, é somente em sua manifestação mesma (por exemplo, numa sequência de números tirados ao azar), que ele se autoinstitui, em ato, como sua própria lei (LANDOWSKI 2005: 65-70).
\end{abstract}

\title{
Assentimento
}

Fundado sobre o princípio do álea, o que se denomina regime do assentimento equivale ao que na terminologia sociossemiótica se chama também regime de acidente. A escolha entre essas duas denominações depende da perspectiva que se adote: seja uma perspectiva «objetivante» que sublinha o caráter imprevisível, aleatório, «acidental» do que advém, seja uma perspectiva em conformidade com o ponto de vista do sujeito que aceita a incerteza da sorte, a possibilidade do acidente, o risco do nonsense. Ao contrário, passa-se para o regime da manipulação quando o sujeito, transformando o álea em uma espécie de destinador, tenta «conjurar a sorte» e orientar o azar a seu favor. Deixa-se igualmente o regime do assentimento, mas para se orientar rumo ao da programação quando se procura capturar, atrás da aparência aleatória do curso das coisas, as regularidades estatísticas que permitem cálculos de probabilidade (LANDOWSKI 2005: 62-65).

\section{Coincidência}

No quadro da problemática geral da interação, distinguem-se na sociossemiótica dois modos de encontro entre actantes. Quando se trata de pôr em relação as intencionalidades (como ocorre no regime da manipulação) ou de pôr em contato as sensibilidades (como ocorre no ajustamento), fala-se de interação propriamente dita. Ao contrário, fala-se em coincidência quando o encontro é o simples cruzamento de dois percursos independentes postos em relação por uma instância terceira, operador (no caso do regime de programação) ou azar (sob o regime do acidente). Nos dois primeiros casos, o resultado da «interação» (stricto sensu) é negociado mediante um processo dinâmico de coordenação entre as competências (modais ou estésicas) dos participantes; nos outros dois, o resultado final 
da «coincidência» é predeterminado pela definição dos papéis temáticos próprios a cada um dos atores que as circunstâncias fazem entrar em conjunção (na programação) ou em colisão (sob o efeito do azar) (LANDOWSKI 2005: 86-91).

\section{O regime do ajustamento}

\section{Ajustamento}

O termo ajustamento designa um dos quatro regimes interacionais definidos pela teoria sociossemiótica. Ajustamento não deve ser confundido com a ideia de adaptação, que remete ao regime da programação (onde um actante pode agir sobre um outro apenas sob a condição de respeitar as regularidades que regem seu comportamento). Não consiste, tampouco, em fazer de modo que um dos actantes se dobre à vontade do outro, como na manipulação. Trata-se de um regime entre iguais, onde os actantes coordenam suas dinâmicas respectivas em função de um princípio de sensibilidade. Ele põe em jogo o processo de contágio fundado sobre as qualidades sensíveis dos parceiros da interação, isto é, de um lado, a consistência estésica (plástica e rítmica) dos objetos, e, de outro, a competência estésica dos sujeitos (LANDOWSKI 2005: 39-52).

\section{Competência estésica}

Diferindo da competência modal que remete à lógica da junção, a competência estésica remete, em sociossemiótica, à lógica da união. Seu exercício supõe, da parte do sujeito, a superação do modo de leitura do mundo definido pelo reconhecimento de unidades figurativas pontuais, e uma disposição para capturar efeitos de sentido oriundos das qualidades plásticas próprias aos objetos apreendidos em sua presença imediata, qualquer que seja seu estatuto actorial (parceiros humanos, obras ou objetos do mundo natural). Obedecendo ao princípio de sensibilidade (e, portanto, independentemente de qualquer intencionalidade orientada por objetivos do tipo «liquidação da falta»), essa competência permite o desenvolvimento do processo de ajustamento recíproco, até o «accomplissement» (desabrochamento) mútuo dos participantes. Expandindo-se à maneira de uma finalidade sem fim — sem alvo preestabelecido —, a competência estésica se constitui na medida mesma em que ela se exerce (LANDOWSKI 2004: 96-99).

\section{Contágio}

Em termos epidemiológicos, o contágio define-se como uma transformação de estado provocada pela transferência de um objeto (o vírus) entre sujeitos: ele obedece à lógica da junção. O conceito sociossemiótico de contágio depende, ao contrário, da lógica da união. Se o rir, o bocejar ou o desejo são ditos contagiosos, é porque, para provocá-los, não é sempre necessário conjugar o interlocutor a algum 
objeto especialmente «risível», «aborrecido» ou «desejável». Ao deixar tão somente transparecer o seu próprio estado hilário, de fastio ou de desejo, um sujeito pode «acender» (como diz Rousseau) o mesmo «fogo» no coração dos que o olham. Sentir o sentir do outro é, em muitos casos, já prová-lo por sua própria conta, como se, por uma espécie de performatividade da copresensa sensível, a percepção das manifestações somáticas de certos estados vividos por outros tenha o poder de nos fazer experimentá-los. O contágio assim entendido como relação entre sensibilidades, intervindo, portanto, no plano estésico, não se confunde com a «imitação» intencional, nem com a «empatia», situada no plano cognitivo (LANDOWSKI 2004).

\section{Estesia}

Introduzida por A. J. Greimas, em Da Imperfeição, a partir de uma reflexão sobre a experiência do "acidente estético», a noção de estesia, uma vez separada daquela de acidente, serve de base, em sociosssemiótica, à definição de um regime de interação específico, aquele chamado de ajustamento. Os processos de ajustamento encontram seu motor na captura, pelos interactantes, dos efeitos de sentido provenientes das qualidades estésicas - da organização plástica e do andamento rítmico — imanentes ao «discurso sensível» que cada um dos parceiros endereça ao outro através da dinâmica de sua presença em movimento (GENINASCA 1984; GREIMAS 1987; FLOCH 1997).

\section{Sensibilidade}

O princípio de sensibilidade funda o que se denomina em sociossemiótica o regime de ajustamento. Nesse quadro, se é levado a reconhecer, ao lado da sensibilidade perceptiva (interoceptiva, proprioceptiva, exteroceptiva) própria aos sujeitos, uma sensibilidade dita reativa, atribuída aos objetos «inanimados», sem a qual não se poderia dar conta das dinâmicas interativas entre homens e máquinas ou entre o homem e seus parceiros do mundo natural, como a neve para o esquiador (LANDOWSKI 2004).

\section{União}

Por oposição à lógica da junção - que condiciona os estados (inclusive passionais) dos sujeitos com as suas relações de conjunção ou de disjunção com objetos autônomos, aptos a circular entre eles -, a lógica da união dá conta de processos de emergência do sentido e do valor que resultam diretamente das relações de copresença sensível, face a face ou corpo a corpo, entre actantes dotados de uma competência estésica. O termo "união" designa, pois, não um estado (nem de conjunção nem de fusão) mas uma dinâmica interacional. Nesse quadro, as relações de interação tomam a forma de ajustamentos recíprocos e tendem para formas de realização mútua nas quais se desenvolve o potencial específico próprio a cada um dos interagentes (GREIMAS \& COURTÉS 1979: 201, 318-319; LANDOWSKI 2004: 58-66). 


\section{O regime da programação}

\section{Programação}

Ver Regularidade, Papel.

\section{Regularidade}

A condição para a existência do regime de interação denominado em sociossemiótica programação é o princípio fundado na regularidade. Tal regularidade remete à constância das relações entre os efeitos (as ações, os comportamentos) e seus determinantes. Ela pode ser garantida, como em física, por relações de causalidade ou por coerções sociais traduzidas sob a forma de regras, de hábitos, de rituais que, uns e outros, acabam definindo papéis temáticos por definição fixos. Fundado sobre esse princípio que constitui a condição de possiilidade de toda previsão, o regime da programação é aquele da repetição do mesmo, da «rotina» e do risco mínimo, mas ao mesmo tempo também aquele do maior fechamento do sentido, podendo mesmo chegar à insignificância (LANDOWSKI 2005: 17-20, 31-34).

\section{Papel}

Ao passo que a noção de papel temático corresponde a percursos de vida estáveis (por exemplo, um «pescador» pesca), a de papel actancial reenvia a competências modais mutantes («querer», e depois, «renunciar»). Em outros termos, um papel temático traduz, pela sua estabilidade, o princípio de regularidade próprio ao regime da programação, enquanto que um papel actancial permite, por sua maleabilidade, dar conta dos confrontos entre intencionalidades sob o regime de manipulação. No regime de ajustamento fundado sobre o princípio de sensibilidade, os sujeitos, dotados de competência estésica exercem papéis existenciais. Sobre o acaso: ainda que desprovido de competência modal ou estésica (nenhuma intencionalidade, nenhuma sensibilidade pode fundar suas «decisões»), ele também tem um papel: produzir acidentes. Mas a maneira aleatória pela qual o regime do assentimento opera contradiz a ideia mesma de papel «temático» (que implica a regularidade) e impõe aquela, antitética, de papel estocástico (não regularidade e imprevisibilidade). Ademais, verdadeiro actante «joker», o acaso preenche também um papel crítico (ele pode decidir o resultado de todo e qualquer processo interacional, qualquer que seja o regime) e um papel catalítico (ele fica isento de qualquer repercussão atada aos efeitos que ele produz). (GREIMAS \& COURTÉS 1979: 52-54, 318-319; LANDOWSKI 2005: 65-71).

\section{O regime da manipulação}

\section{Manipulação}

Ver A.J. Greimas e J. Courtés, Sémiotique. Dictionnaire raisonné de la théorie $d u$ langage, Paris, Hachette, 1979 (Trad. port. Dicionário de Semiótica. São Paulo. Ed. Contexto, 2004) e E. Landowski, Les interactions risquées, Limoges, Pulim, 2005. 
Eric Landowski, director de pesquisa associado ao Cevipof (Paris, CNRS-Sciences Po) e ao CeReS (Universidade de Limoges), é codiretor da revista Actes Sémiotiques, codiretor do Centro de Pesquisas Sociossemiótica de São Paulo e professor convidado da Universidade de Vilnius. Entre suas principais publicações estão: A sociedade refletida (Educ-Pontes, 1991); Presenças do outro (Perspectiva, 2002); Passions sans nom (P.U.F., 2004) e Les interactions risquées (PULIM, 2005).

eric.landowski@sciencespo.fr

\section{Referências}

FLOCH, J.-M. 1995: Identités visuelles, Paris, PUF. 1997: Lecture de Tintin au Tibet, Paris, PUF.

GENINASCA, J. 1984: "Le regard esthétique », Actes Sémiotiques-Documents, VI, 58 (rééd. in La parole littéraire, Paris, PUF, 1997).

GREIMAS, A.J. 1976: Sémiotique et sciences sociales, Paris, Seuil. 1987: De I'Imperfection, Périgueux, Fanlac.

. et J. COURTÉS 1979: Sémiotique. Dictionnaire raisonné de la théorie du langage, Paris, Hachette (rééd.1993).

LANDOWSKI, E. 1989: La société réfléchie. Essais de socio-sémiotique, Paris, Seuil. . 1997: Présences de I'Autre. Essais de socio-sémiotique II, Paris, PUF. 2004: Passions sans nom. Essais de socio-sémiotique III, Paris, PUF. 2005: Les interactions risquées, Limoges, Pulim. .2007: «Unità del senso, pluralità di regimi », in G. Marrone (dir.), Narrazione ed esperienza, Rome, Meltemi.

MARRONE, G. 2001: Corpi sociali, Turin, Einaudi.

MARSCIANI, F. 2007: Tracciati di etnosemiotica, Milan, Angeli. 